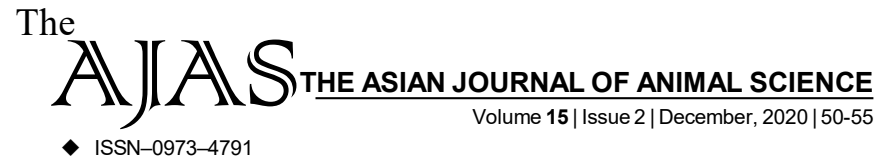

\title{
Effect of wheatgrass biscuits on hematology of wistar albino
}

\section{rats}

Suneetha Runjala and Y.L.N. Murthy

Author for Corresponding -

Suneetha Runjala Acharya Nagarjuna University, Guntur (A.P.) India Email:srunjala@yahoo.com
ABSTRACT...... The exploitation of herbal -based inhibitor compounds in food stuffs and medicine are gaining a good deal of interest due to potential health advantages. Recent researchers have attempted the exploration of traditional and plant-based therapeutical and medicinal preparations using bio-chemical analyses and in-vitro experimentation. The effect of wheatgrass biscuits on hematological parameters were studied in Wistar albino female rats for 21 days. The wheatgrass powder 20,30 and $40 \mathrm{~g}$ per $100 \mathrm{~g}$ incorporated biscuits prepared into pellet form labelled as V2, V3 and V4 formula supplemented to 3 sample groups normal laboratory diet to 1 control group under laboratory conditions. The average mean food efficiency during 21 days of supplementation recorded that control group has the highest efficiency food intake than sample groups. Group 3 has the lowest efficiency intake fed with $\mathrm{V} 4$, than group 1 and group 2 fed with V2 and V3. The results showed significant increase in RBC, WBC, Hematocrit, MCV and decreased levels of MCH in all groups. At the end of the study microflora contamination was estimated by using fecal collection of rats. Lactobacilli colonies were 6 to $7 \mathrm{cfu} / \mathrm{g}$ were identified as creamy white and small colonies on lactobacilli as Gram positive on MRS agar plates, which are under permissible limits. Less bacteria indicates that rats are not affected by any food poising during 21 days. E. coli colonies exhibited a metallic sheen on Sabouraud's agar medium and counted 2 to $3 \mathrm{cfu} / \mathrm{g}$ appeared as shiny white colonies as gram negative. Yeast appears as gram-positive globules. It was found that the wheatgrass biscuits effectively improved normal haematological and physical body parameters without signs of 1any abnormalities.

KEY WORDS...... Wheatgrass biscuits, RBC, WBC, MCV, MCH, L. bacilli, E.coli, Yeast

HOW TO CITE THIS ARTICLE - Runjala, Suneetha and Murthy, Y.L.N. (2020). Effect of wheatgrass biscuits on hematology of wistar albino rats. Asian J. Animal Sci., 15(1): 50-55.DOI:10.15740/ HAS/TAJAS/15.2/50-55.Copyright@2020:HindAgri-Horticultural Society.

ARTICLE CHRONICLE - Received : 15.06.2020; Revised : 07.10.2020; Accepted : 05.11.2020 